\title{
The Silencing of LGBTQ Older Adults' Identities through Ageing in Long-Term Care
}

\author{
Shauna Wallace
}

I ESBIAN, gay, bisexual, transgender, and queer $\perp$ (also known as LGBTQ) activists have done instrumental work to challenge public stigma over the last several decades in order to advance LGBTQ rights. Although this activism work has initiated significant social change, pioneers of this movement, among many other LGBTQ ageing individuals, often find themselves disenfranchised as they age and seek appropriate long-term housing and care. As the ageing population grows, so does the urgency to provide accessible long-term care that supports the diversity of its residents. Thus, it is imperative to establish a standard of care with an emphasis on training staff and residents to encourage respectful and equitable treatment of LGBTQ residents.

Through my analysis, disadvantages to LGBTQ older adults as it relates to long-term care, will be discussed through social, gerontological, cultural, and healthcare perspectives. I will underline how ageing as an LGBTQ individual is a social process by explaining how social theories can support, as well as limit changes in the LGBTQ experience. I will use life course, feminist, and queer theory to inform my analysis. Further, I will use feminist and queer theory to critically examine institutional and societal patterns in treatment of the ageing LGBTQ community, as well as how LGBTQ older adults can be marginalized by the theories themselves.
I will then use life course theory to address cumulative disadvantages according to two of its main principles, lives in time and place and human action within constraint.

External sources will provide the current paper with a strong foundation of social theories, while supplementary research will provide me a comprehensive lens to examine contemporary issues regarding LGBTQ ageing. Therefore, throughout this paper, the need for improved provision of long-term care for LGBTQ older adults in Western culture will be emphasized through discussion of relevant social theories as well as social factors contributing to the current climate of long-term care for the aforementioned population: discriminatory attitudes, a shifting landscape of social support, and competency of care.

\section{A Contemporary Issue: LGBTQ Long- Term Care}

The current analysis was inspired by a 2018 Globe and Mail article entitled "LGBTQ seniors fear renewed discrimination in long-term care". This article provides first-hand accounts of the treatment of LGBTQ individuals in long-term care. Here, these individuals often experience significant social isolation due to heterosexual older adults' minimal experiences with them, 
which cause tension and prejudicial attitudes. It captures the diversity of experiences of LGBTQ individuals in long-term care homes; a stark contrast exists between the lack of acceptance faced by 81-year old David McClure with the 'openarmed' welcome experienced by 62 -year old Paul Leroux. It then explains that the deficiencies in training staff on LGBTQ issues can quickly lead to differential and prejudicial treatment. This environment can foster anxiety in LGBTQ residents and may prevent them from identifying as LGBTQ for fear of mistreatment. The article references social activities like drag shows and Pride festivals, which can help facilitate positive contact among staff and residents (Ibbitson, 2018). Experiences like McClure's, though, are not uncommon, as discrimination for an LGBTQ individual starts much earlier in their life than at the point when long-term care becomes a concern.

\section{Discrimination And Identity Silencing}

Common adverse life experiences highlighted as most significant by ageing LGBTQ individuals include, but are not limited to, mental health problems, addictions, severe economic hardship, and encountering bias due to discrimination (Fredriksen-Goldsen, Muraco, Kim, Goldsen, \& Jen, 2016). The comorbidity of these experiences suggests a correlational relationship between them, which is most likely influenced by discrimination and prejudiced viewpoints. A unique challenge is presented since the intersection of ageism and homophobia or transphobia often excludes LGBTQ older adults from public and scholarly discourse, silencing their voices (Glenn, 2004; as cited in Brown, 2009). Older adults are typically viewed as asexual and LGBTQ individuals are viewed as hypersexual. Because of this, LGBTQ older adults are overwhelmingly ignored by the public and overlooked by the larger LGBTQ community (Abatiell \& Adams, 2011), this contributes to the public stigma since these individuals often do not fit into either group and feel ostracized as a result.

QueER AND Feminist TheORY
Ostracism is not limited to exclusionary social discourse, as scholarly works can also exclude LGBTQ individuals from academic discourse. For example, as a subset of critical theory, queer theory works in conjunction with feminist theory to challenge heteronormative narratives in social gerontology. Some may feel ostracized from queer theory due to the violent and oppressive history of the term 'queer' itself, while others feel that normative ideologies of age and class still exist within the theory, which elevates the white male experience. The lack of acknowledgement of older adults in queer theory as well as separately in gerontological theories can leave them feeling disenfranchised and lacking adequate social and material supports (Halberstam, 2005; as cited in Brown 2009).

Feminist theory also excludes LGBTQ individuals from its narrative in a similar way. Feminist theory seeks to explain how gender hierarchies are sustained. In this theory, women are seen as disadvantaged through inherently gendered patriarchal systems, and these gender inequities are seen as institutionalized, exacerbated by dynamic forces which in turn, influence individual choices (Estes, 2004; as cited in Wister \& McPherson, 2014). Although the theory aims to promote equality across genders, it neglects to do so with LGBTQ older adults as they are not mentioned in this theory and even less so in scholarly literature from a theoretical lens (Kia, 2016). Transgender identity and sexuality in LGBTQ older adults are similarly ignored, perpetuating more dominant heteronormative theories and myths of ageing (Brown, 2009).

One problematic aspect of cultural discourse that may influence LGBTQ exclusion from these theories is assumptions made about LGBTQ identities based on stereotypes and generalizations. With regards to conceptualizing LGBTQ identities, it is imperative to differentiate between individual experiences and sexualities. Therefore, a greater effort must be made to dispel myths surrounding the existence of a single normative and all-encompassing LGBTQ 
identity. This identity tends to propagate the archetypal LGBTQ individual as a youthful radical, creating a disconnect between group and personal LGBTQ identities. This relative invisibility of LGBTQ older adults that do not fit this description, in comparison with the more dominant young LGBTQ individuals, suggests a need for realignment of cultural expectations of LGBTQ identity on both a group and personal level (Brown 2009; Knauer, 2011; as cited in Abatiell \& Adams, 2011).

\section{Life Course Theory}

In addition to the aforementioned theories, life course theory can also be applied to LGBTQ individuals in ageing. Although LGBTQ individuals are not explicitly mentioned in life course theory, it can be applied as a means of identifying how one's biography and history are bridged by considering significant life transitions, trajectories, and turning points. Two of its principles are particularly relevant: lives in time and place and human action within constraint. Lives in time and place refers to the historical and geographical settings which impact individual experience. For example, prejudicial attitudes towards an LGBTQ older adult might have been more heavily emphasized a century ago or in a more conservative Eastern European country compared to current attitudes, but conversely, may be much less exaggerated in the future as attitudes continue to progressively shift towards acceptance of diversity.

Next, human action within constraint refers to the idea that lives are constructed within the parameters of individual social experiences. A relevant example is an 'out' LGBTQ older adult that is unable to afford a more accepting longterm care home due to insufficient private funds and as such, their agency is limited. This may be the result of systemic and life-long discrimination, resulting in impoverishment (Wiger, 2015; Westwood, 2016). In this case, cumulative consequences of institutionalized prejudice led to an increased risk of being in a financially unstable state (Abatiell \& Adams, 2011).
Although life course theory can illuminate several disparities and systemic prejudices in the current system of care, it too lacks the queer perspective. This theory may benefit from being expanded to include discussion of how one's social location can affect their LGBTQ identity throughout the life course. It might also incorporate examples of non-traditional family structures and include discussion of more diverse life paths that are not limited to family, education, and work progression. Aspects of queer life such as turning points, like coming out, and transitions, like sex-reassignment surgeries, are currently excluded from the heteronormative model of life course theory. This effectively silences the perspective of LGBTQ older adults, invalidating their diverse trajectories (Brown, 2009).

\section{Shifting Landscape of Social Support:} FORMAL Supports

In the current landscape of long-term care, LGBTQ older adults are considered some of the most critically underserved and at-risk populations. The same individuals who may have led a revolutionary movement to demand equality are once again having to demand equality in provision of appropriate long-term care. This is largely due to a general neglect in policy and program development (Abatiell \& Adams, 2011). Many have grown accustomed to denying their own identities in order to appease caregivers, this is largely due to the lack of acceptance in formal care settings. In fear of mistreatment, these individuals often do not disclose their LGBTQ identities as an unconscious response to previous trauma (Westwood, 2016).

The tendency to pathologize individuals is another problematic, yet prevalent practice in caregiving and the healthcare system. For instance, gender non-conforming or transgender individuals may feel disrespected and invalidated by the DSM-V (Diagnostic and Statistical Manual of Mental Disorders, 5th Edition) classification of gender dysphoria, just as individuals 
identifying as gay might have felt 'disordered' by the previous classification of homosexuality as a psychological disorder in the DSM-III (Westwood, 2016). Institutions can silence identities simply by ignoring or pathologizing them, which promotes a heteronormative ideal (Foucault, 1978; as cited in Brown 2009; Willis, 2017).

Examples of this systemic neglect are quite evident through examining formal social supports for ageing LGBTQ individuals. Some examples of formal supports that are often inaccessible to LGBTQ older adults include Social Security and Medicaid 'safety nets' in the United States. Further, acquiring correct documentation that agrees with gender presentation, and is necessary to access these services, may be very time-consuming and expensive to acquire. Additionally, there is a general lack of policies protecting LGBTQ older adults in long-term care homes. As an example, there are often minimal policies surrounding placement of LGBTQ individuals in same-sex bedrooms that contradict their self-identified gender and presentation (Porter et al., 2016).

Shifting LANDScape of Social Support: INFORMAL SUPPORTS

LGBTQ individuals also lack informal social support systems. Frequent cutting of familial ties and estrangement due to disapproval of 'lifestyle' factors associated with identifying as LGBTQ leads to increased reliance on 'families of choice', which consist of friends, partners, and other non-familial supports that tend to weaken with age. LGBTQ older adults are twice as likely as their heterosexual counterparts to live alone, $75 \%$ less likely to have children, and even fewer are involved in long-term relationships (Abatiall \& Adams, 2011; Wiger, 2015). In addition to this, before the advent of antiretroviral drugs, and during the HIV/AIDS epidemic, LGBTQ individuals were not expected to live as long as they do now. As a result, after the HIV/AIDS epidemic, there were fewer intergenerational relationships remaining in the LGBTQ community (Wiger, 2015).

\section{Competency in Care: Healthcare Con-} CERNS

Support for LGBTQ individuals is also lacking in the social services sector. Due to medical advances over the years, development of antiretroviral treatments has led to a rise in HIV-positive individuals living over the age of 50. This is significant since the death rate from HIV has significantly declined in recent years. From 2005 to 2015, the death rate from HIV was almost halved from 2 million to 1.1 million (Roser \& Ritchie, 2018). Despite the improved longevity due to medical advances and the decriminalization of LGBTQ relationships, attitudes regarding LGBTQ issues remain slow to change. LGBTQ individuals often find themselves lacking adequate support as social services are slow to respond to their needs (Abiell \& Adams, 2011).

As such, the desexualisation of older adults leads to a diminished rate of testing for sexuallytransmitted infections (STIs) and diseases, like HIV, despite the higher rate of sexually-risky behaviours such as not using condoms during intercourse. The combination of the perception that older adults are not sexually active, and HIV symptoms being frequently misdiagnosed as common illnesses, results in a significant delay in diagnosing HIV from its onset. Therefore, ignorance of LGBTQ healthcare needs can perpetuate the spread of HIV and lead to neglect of sexual health in general (Abiell \& Adams, 2011).

Competency in Care: Attitudes in CareGIVING

Several systemic issues in caregiving, and healthcare as discussed above, of LGBTQ older adults can stem from prejudicial attitudes. Many North American caretakers show obvious signs of disapproval or abuse towards LGBTQ individuals. Canada was the first country in North America to legalize same sex marriage in 2005, and as such, Canadian social policy must now follow suit by offering appropriate support 
in older age. In the United States, discrimination is currently only illegal in $50 \%$ of states. This may permit heightened prejudicial attitudes to continue. Thus, a lack of enforced action against discriminatory behaviours perpetuates a general hostility towards LGBTQ individuals (Wiger, 2015).

This hostility can be targeted with diversity and sensitivity training, which will help to make staff more knowledgeable and aware of, as well as welcoming to LGBTQ older adults (Wiger, 2015). While competency training is gaining traction in certain institutions, unfortunately, diversity training is insufficiently prioritized and non-mandatory, and one training session is hardly enough to combat systemic issues of prejudicial treatment (Westwood \& Knowcker, 2016; as cited in Westwood, 2016). The lack of adequate provision of care demonstrated through insufficient training can be viewed as a denial of human rights and resistance of equality. This is because LGBTQ individuals have the equal right to long-term housing and care that is respectful and responsive to their specific needs; an equitable and just ask, as non-LGBTQ individuals receive this same right without question (Westwood, 2016).

Competency in Care: Suggestions for Future Advocacy and Education

In work advocating for celebrating the diversity of the LGBTQ community, recognizing individual differences is an important aspect of delivering effective care. A crucial facet of this care is acknowledging the agency and diverse needs of LGBTQ older adults. Competency in care for LGBTQ individuals is contingent upon the sensitivity and diversity training that caregivers and service providers receive. Educating caregivers regarding LGBTQ needs at the theoretical level is a crucial step in being able to apply this knowledge in program development. Wiger (2015) suggests expanding services to offer a 'Rainbow Information Fair' for the purpose of educating long-term care staff and fellow residents, encouraging shifting attitudes towards
LGBTQ individuals and promoting inclusivity.

In the current literature, LGBTQ older adults are largely understudied, and further research is needed to appropriately map the needs of these individuals. One challenge in data collection is that these individuals are often apprehensive to 'out' themselves in fear of mistreatment (Abatiell \& Adams, 2011), remaining invisible as a means of protecting themselves from discriminatory expressions (Willis, 2017). It is crucial to promote visibility and markers of inclusion for LGBTQ individuals by using promotional materials in long-term care homes to communicate acceptance of diverse families outside of the heteronormative expectation. Further research is needed to investigate the effectiveness of these visibility strategies through longitudinal case studies (Willis, 2017).

\section{Overcoming Limitations AND Opposition}

Although increased visibility of LGBTQ individuals can decrease stigma, increased visibility strategies may not be the preferred solution for everyone. Perhaps not all LGBTQ older adults desire to be open about their identities, and thus do not care to be active members of the greater LGBTQ community. This may be in part because they view their LGBTQ identity as only a small fraction of their whole identity as a person. Also, risks associated with being 'out' may be quite serious, depending on one's context. Due to religious and cultural ideals, as well as personal misconceptions about LGBTQ individuals, there may be systemic resistance to change in political and corporate climates. This can be reflected by the lack of support for diverse identities of LGBTQ older adults in long-term care homes.

For example, in 2017, U. S. President Donald Trump removed the LGBTQ community from The National Survey of Older Americans Act Participants and the Annual Program Performance Report for Centers for Independent Living. These surveys are integral in informing caregiving practices for older adults (Anderson, 
2017). This further demonstrates how living in a radically conservative climate that is not affirming of non-heteronormative identities can actively oppress and stifle voices of marginalized groups. This type of action can effectively erase LGBTQ older adults from the fabric of history.

In the case that LGBTQ older adults choose to keep their identities private, caregivers can still support them by partaking in an accepting and open helping relationship. General recommendations for caregivers of LGBTQ older adults include respecting boundaries, helping clients to navigate difficult emotions regarding a transition to long-term care, validating concerns of how intersectionality can impact a LGBTQ older adult's social location, and using inclusive and culturally-specific language (e.g. TwoSpirit for some Aboriginal persons) (Porter et al., 2016).

\section{Concluding Thoughts}

Through this critical analysis, the urgent need for a reform in LGBTQ long-term care was discussed. Exclusion of LGBTQ individuals from narratives of social theories such as queer, feminist, and life course theories commonly drawn on in gerontology are in part to blame for this gap in care. This is because education and programming reforms often rely on research and scholarly theories to communicate improvements that need to be made. It is pertinent to consider how cumulative disadvantages and social factors over the life span, such as the instability of chosen families, financial insecurity, and systemic discrimination, make LGBTQ older adults particularly vulnerable to neglect in long-term care facilities. Furthermore, systemic discrepancies in healthcare as well as caregiving attitudes towards LGBTQ older adults leads to these individuals being discriminated against regularly and they may find it difficult to mobilize resources to protect themselves due to inadequate social supports. Therefore, exclusion of marginalized LGBTQ older adults effectively silences their voices, leading to inaction and complacency in long-term care reform. It is crucial to maintain sensitivity in engaging with LGBTQ voices by acknowledging individual agency and differing needs, as some self-expression requires LGBTQ individuals to become vulnerable and may trigger anxiety as a result (Willis, 2017).

In summary, a 'one size fits all' approach is not an effective model for provision of long-term supportive care for LGBTQ older adults. As an active and engaged citizen, one can also do their part to promote acceptance of diversity by using inclusive language with everyone, but older adults especially. Individuals can use terms like 'partner' instead of 'boyfriend' or 'girlfriend' to promote open and safe conversation as well as avoid making assumptions regarding sexual preferences or gender identities of older adults. Additionally, individuals can vote for political candidates who do not diminish the LGBTQ perspective and instead, choose to honour and empower it. Lastly, since many older adults tend to have aversive attitudes towards LGBTQ individuals due to lack of exposure, individuals that consider themselves allies must challenge prejudicial attitudes. Allies can do this by vowing to address discrimination in public and private discourse while challenging prejudiced behaviours, especially in the presence of older adults.

\section{AUthor BIOGRAPHY}

Shauna is a recent graduate of the Bachelor of Arts \& Sciences program at the University of Guelph, with an arts specialization in Family and Child Studies and a science specialization in Psychology: Brain \& Cognition. During this time, she has also earned a certificate in Spanish Language and Culture. She began writing the current piece as a commentary on disparities in systems of older adult care for Prof. Kelsey Harvey's Social Gerontology course. She was motivated in her writing by her passion for advocating for minority groups commonly overlooked and underserved. 
She hopes to continue advocating for issues of social location by learning more about specialized and trauma-informed care through a graduate degree in Counselling and Psychotherapy. 


\section{Works Cited}

Abatiell, P., \& Adams, M. (2011). LGBT aging: A question of identity. The Gerontologist,51(6), 880-884. doi:10.1093/geront/gnr113

Anderson, D. (2017, March 20). Trump administration removes LGBTQ seniors from federal care surveys. States News Service. Retrieved from http://link.galegroup.com.subzero.lib.uoguelph.ca/ apps/doc/A487032031/AONE?sid=googlescholar

Brown, M. T. (2009). LGBT aging and rhetorical silence. Sexuality Research and Social Policy,6(4), 65-78. doi:10.1525/srsp.2009.6.4.65

Fredriksen-Goldsen, K., Muraco, A., Kim, H., Goldsen, J., \& Jen, S. (2016). Unfolding LGBT lives: Key life experiences and the life course. The Gerontologist, 56(3), 653. doi:10.1093/geront/gnw1 62.2653

Ibbitson, J. (2018, August 7). LGBTQ seniors fear renewed discrimination in long-term care. The Globe and Mail. Retrieved from https://www.theglobeandmail.com/politics/article-lgbtqseniors-fear-renewed-discrimination-in-long-term-care/

Kia, H. (2016). Hypervisibility: Toward a conceptualization of LGBTQ aging. Sexuality Research E Social Policy; Berkeley, 13(1), 46-57. http://dx.doi.org.subzero.lib.uoguelph.ca/10.1007/s13178-015-0194-9

Porter, K. E., Brennan-Ing, M., Chang, S. C., Dickey, L. M., Singh, A. A., Bower, K. L., \& Witten, T. M. (2016). Providing competent and affirming services for transgender and gender nonconforming older adults. Clinical Gerontologist. Retrieved from https://www.tandfonline.com.subzero.lib.uoguelph.ca/doi/abs/10.1080/07317115.2016.1203383

Roser, M., \& Ritchie, H. (2018). HIV / AIDS. Our World in Data. Retrieved from https://ourworldindata.org/hiv-aids

Westwood, S. (2016). LGBT* ageing in the UK: Spatial inequalities in older age housing/care provision. Journal of Poverty and Social Justice,24(1), 63-76. doi:10.1332/175982716x14538098308249

Willis, P. (2017). Queer, visible, present: The visibility of older LGB adults in long-term care environments. Housing, Care and Support,20(3), 110-120. doi:10.1108/hcs-04-2017-0007

Wiger, R. (2015, August). The silver rainbow: societal challenges facing LGBTQ seniors. Parks $\mathcal{E}$ Recreation, 50(8), 50+. Retrieved from http://link.galegroup.com.subzero.lib.uoguelph.ca/apps/ doc/A427757108/AONE?u=guel77241\&sid=AONE\&xid=986f480b

Wister, A., \& McPherson, B. D. (2014). Aging as a social process: Canadian perspectives. Don Mills, ON: Oxford University Press. 